\title{
Генерация терагерцевого излучения в низкотемпературных эпитаксиальных пленках InGaAs на подложках InP с ориентациями (100) и (411) A
}

\author{
(С) Г.Б. Галиев ${ }^{1}$, М.М. Грехов ${ }^{3}$, Г.Х. Китаева ${ }^{2}$, Е.А. Климов ${ }^{1}$, А.Н. Клочков ${ }^{1}$, О.С. Коленцова ${ }^{3}$, \\ В.В. Корниенко ${ }^{2}$, К.А. Кузнецов ${ }^{2}$, П.П. Мальцев ${ }^{1}$, С.С. Пушкарев ${ }^{1}$ \\ ${ }^{1}$ Институт сверхвысокочастотной полупроводниковой электроники Российской академии наук, \\ 117105 Москва, Россия \\ ${ }^{2}$ Московский государственный университет им. М.В. Ломоносова (физический фракультет), \\ 119991 Москва, Россия \\ ${ }^{3}$ Национальный исследовательский ядерный университет „МИФИ“ \\ 115409 Москва, Россия \\ E-mail: galiev_galib@mail.ru
}

(Получена 10 мая 2016 г. Принята к печати 18 мая 2016 г.)

\begin{abstract}
Методом терагерцевой спектроскопии временно́го разрешения исследованы спектр и волновые формы импульсов широкополосного терагерцевого излучения, генерируемых низкотемпературными эпитаксиальными пленками $\operatorname{In}_{0.53} \mathrm{Ga}_{0.47} \mathrm{As}$ при накачке фемтосекундными лазерными импульсами. Пленки $\operatorname{In}_{0.53} \mathrm{Ga}_{0.47} \mathrm{As}$ были получены методом молекулярно-лучевой эпитаксии при температуре $200^{\circ} \mathrm{C}$ и при различных давлениях мышьяка на подложках InP с ориентацией (100) и впервые на подложках InP с ориентацией (411)A. Исследованы морфология поверхности образцов с помощью атомно-силовой микроскопии и их структурное совершенство с помощью высокоразрешающей рентгеновской дифрактометрии. Обнаружено, что амплитуда терагерцевого излучения от слоев LT-InGaAs на подложках InP (411)A в 3-5 раз больше, чем от таких же слоев на подложках InP (100).
\end{abstract}

DOI: $10.21883 /$ FTP.2017.03.44201.8312

\section{1. Введение}

В последние годы широко исследуются фотопроводящие антенны для приема и передачи электромагнитных сигналов терагерцевого диапазона частот (от 100 Гц до 10 ТГц) на основе эпитаксиальных соединений $\mathrm{A}^{\mathrm{III}} \mathrm{B}^{\mathrm{V}}$, выращенных в низкотемпературном режиме. Одним из первых таких материалов был низкотемпературный $\mathrm{GaAs}$ (low-temperature GaAs, LT-GaAs). Он обладает ультракоротким временем жизни фотовозбужденных носителей заряда, большим темновым удельным сопротивлением и хорошей подвижностью электронов [1]. На основе LT-GaAs сделано большое количество действующих устройств [2].

Низкотемпературный рост приводит к встраиванию избыточных атомов мышьяка As в кристаллическую решетку LT-GaAs и к образованию дефектов: антиструктурных дефектов - атом мышьяка в узле атома галлия $\mathrm{As}_{\mathrm{Ga}}$, межузельных атомов $\mathrm{As}_{i}$, вакансий галлия $V_{\mathrm{Ga}}$. За захват фотовозбужденных электронов и уменьшение их времени жизни главным образом, ответствен дефект $\mathrm{As}_{\mathrm{Ga}}$ [3]. Но для осуществления захвата электрона дефект $\mathrm{As}_{\mathrm{Ga}}$ должен находиться в заряженном состоянии $\mathrm{As}_{\mathrm{Ga}}^{+}$, т. е. атом мышьяка должен отдать пятый внешний электрон. Для увеличения концентрации заряженных дефектов $\mathrm{As}_{\mathrm{Ga}}^{+}$материал LT-GaAs легируют акцепторной примесью (как правило, бериллием) [4]. В работах [3,5,6] показано, что при определенных уровнях легирования (от $5 \cdot 10^{17}$ до $2 \cdot 10^{19} \mathrm{~cm}^{-3}$ ) Be:LT-GaAs структуры могут быть использованы в оптоэлектронных устрой- ствах терагерцевого диапазона частот, причем такие устройства имеют лучшие параметры по сравнению с устройствами на базе нелегированного LT-GaAs. Однако из-за высокой токсичности Ве его использование при молекулярно-лучевой эпитаксии (МЛЭ) требует дополнительных мер безопасности. Кроме того, наличие в установке МЛЭ источника Ве приводит к повышению фоновой примеси $p$-типа, что отрицательно сказывается на качестве других гетероструктур, выращиваемых в этой установке.

В работах [7-12] было показано, что из-за свойства амфотерности атомов кремния в GaAs c ориентацией $(n 11)$ А, где $n=1,2,3 \ldots$, методом МЛЭ в высокотемпературном режиме можно вырастить эпитаксиальные пленки как с $n$-, так и $p$-типом проводимости. Тип проводимости зависит от давления мышьяка в процессе МЛЭ роста. На основе этих результатов продемонстрирована возможность получения планарного $p-n$-перехода при МЛЭ росте на подложках GaAs с ориентацией (111)A и использовании в качестве легирующей примеси только $\mathrm{Si}[13,14]$. Нам неизвестны работы, в которых исследовалось влияние полярной ориентации подложки (n11)A на тип проводимости легированных $\mathrm{Si}$ пленок GaAs при низкотемпературном эпитаксиальном росте, а также работы, в которых исследовались аналогичные эффекты для пленок InGaAs на подложках InP. Недавно нами впервые были представлены результаты исследований структурных и фотолюминесцентных свойств LT-GaAs структур на подложках GaAs (111)A и $(100)[15,16]$. 


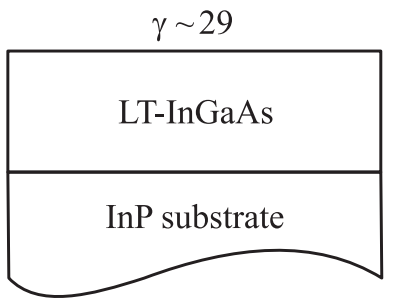

983

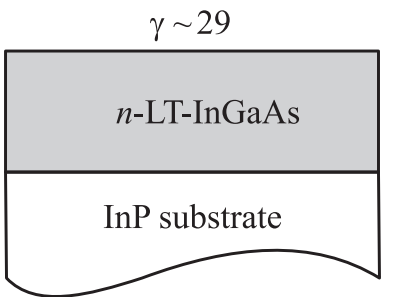

984

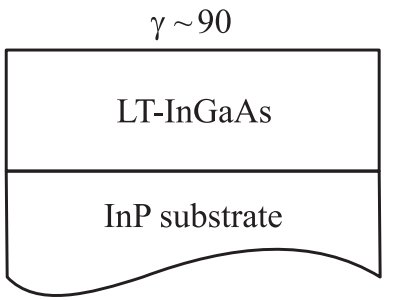

985

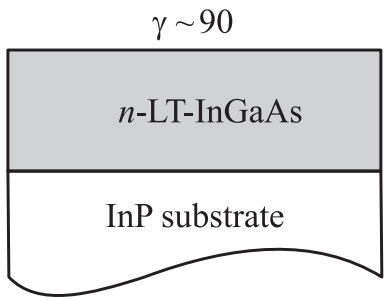

986

Рис. 1. Дизайн образцов, $\gamma=P_{\mathrm{As}} /\left(P_{\mathrm{Ga}}+P_{\mathrm{In}}\right)$.

Одним из факторов, сужающих область применения фотопроводящих антенн на основе LT-GaAs, является большая ширина запрещенной зоны GaAs $\left(E_{g}=1.424\right.$ эВ, длина волны накачки $\left.\lambda \leq 871 \mathrm{Hм}\right)$. Это обстоятельство ограничивает выбор фемтосекундных лазерных источников, способных работать с такой антенной. В связи с этим актуальна задача разработки материалов, которые могут быть совмещены с доступными и недорогими лазерами, используемыми в линиях волоконной связи (1.3 и 1.55 мкм), и которые в то же время обладают всеми достоинствами LT-GaAs, указанными выше.

Одним из подходящих материалов является InGaAs c малой шириной запрещенной зоны (для $\operatorname{In}_{0.53} \mathrm{Ga}_{0.47} \mathrm{As}$ $E_{g}=0.718$ эВ, длина волны накачки $\lambda \leq 1.727$ мкм [17]). Однако даже нелегированные эпитаксиальные пленки LT-InGaAs обладают высокой концентрацией электронов проводимости $\left(\sim 10^{17} \mathrm{~cm}^{-2}\right)$ и низким темновым сопротивлением. Поэтому одной из фундаментальных проблем в этой области является разработка таких технологических условий получения пленок InGaAs, которые обеспечивают параметры, требуемые для фотопроводящих терагерцевых антенн: малое время жизни фотовозбужденных носителей заряда и как можно более высокое темновое удельное сопротивление

Исследования в данной области сосредоточены в следующих направлениях:

1) ионная бомбардировка пленок InGaAs высокоэнергетическими ионами $[18,19]$;

2) легирование слоя InGaAs акцепторами Ве при низкотемпературной эпитаксии $[20,21]$ или примесями, создающими глубокие уровни (Fe) [22];

3) формирование в эпитаксиальных пленках LT-InGaAs периодически расположенных наноразмерных островков ErAs толщиной 0.2-2 монослоя [23-25].

Суть данного исследования заключается в следующем. При использовании подложек InP с ориентацией $(n 11) \mathrm{A}$, где $n=1,2,3 \ldots$, появляется возможность, как и при использовании подложек GaAs (111)A, технологически управляемого осаждения атомов кремния на узлы решетки элементов либо III, либо V группы, из-за чего они становятся либо донорами, либо акцепторами электронов. Управление встраиванием происходит в процессе МЛЭ с помощью изменения давления мышьяка либо концентрации легирующей примеси. Благодаря этому можно добиться увеличения удельного сопротивления
LT-InGaAs и увеличения концентрации ловушек электронов, связанных с антиструктурными дефектами.

\section{2. Образцы и методика эксперимента}

Исследуемые образцы были выращены методом МЛЭ на полуизолирующих подложках InP, легированных $\mathrm{Fe}$. Дизайн образцов представлен на рис. 1, они представляют собой слои LT- $\mathrm{In}_{0.53} \mathrm{Ga}_{0.47} \mathrm{As}$ толщиной 1.2 мкм на подложках InP двух разновидностей: с кристаллографической ориентацией поверхности (100) и (411)А. Выращенные образцы были нелегированными и однородно легированными кремнием. При выращивании легированных образцов (984 и 986) температура кремниевой ячейки составляла $1040^{\circ} \mathrm{C}$, что соответствует объемной концентрации электронов при высокотемпературном росте $n$-GaAs на подложке GaAs (100) 4-5 $10^{17} \mathrm{~cm}^{-3}$.

Для достижения максимальной идентичности технологических условий (температуры роста $T_{g}$ и соотношения потоков элементов V и III групп $\gamma$ ) в одном процессе на держатель образца монтировались две половины подложек разного типа. Образцы 983 и 984 были выращены при $\gamma \sim 29$, а образцы 985 и 986 при $\gamma \sim 90$. Температура роста LT-InGaAs слоев для всех образцов была одинаковой и составляла $200^{\circ} \mathrm{C}$. После роста образцы подвергались отжигу в камере роста установки МЛЭ в потоке $\mathrm{As}_{4}$ при температуре $500^{\circ} \mathrm{C}$ в течение 1 ч. Образцы на подложках InP (100) будут обозначаться как 983-O, 984-O, 985-О, 986-О, а образцы на подложках InP (411)А - как 983-А, 984-А, 985-А, 986-А.

Морфология поверхности образцов исследовалась методом атомно-силовой микроскопии (АСМ) на микроскопе Solver Next (НT МДТ), а измерения кривых дифракционного отражения (КДО) были выполнены на дифрактометре Ultima IV (Rigaku).

Исследования генерации терагерцевого электромагнитного излучения в слоях LT-InGaAs проводились на образцах, подвергнутых высокотемпературному отжигу. Схема установки для терагерцевой спектроскопии временно́го разрешения (ТСВР) приведена на рис. 2. Источником импульсов оптического излучения служил волоконный фемтосекундный $\mathrm{Er}^{3+}$-лазер с длиной волны 1.56 мкм, длительностью импульсов 100 фс и частотой повторения 70 МГц. После прохождения фокусирую- 


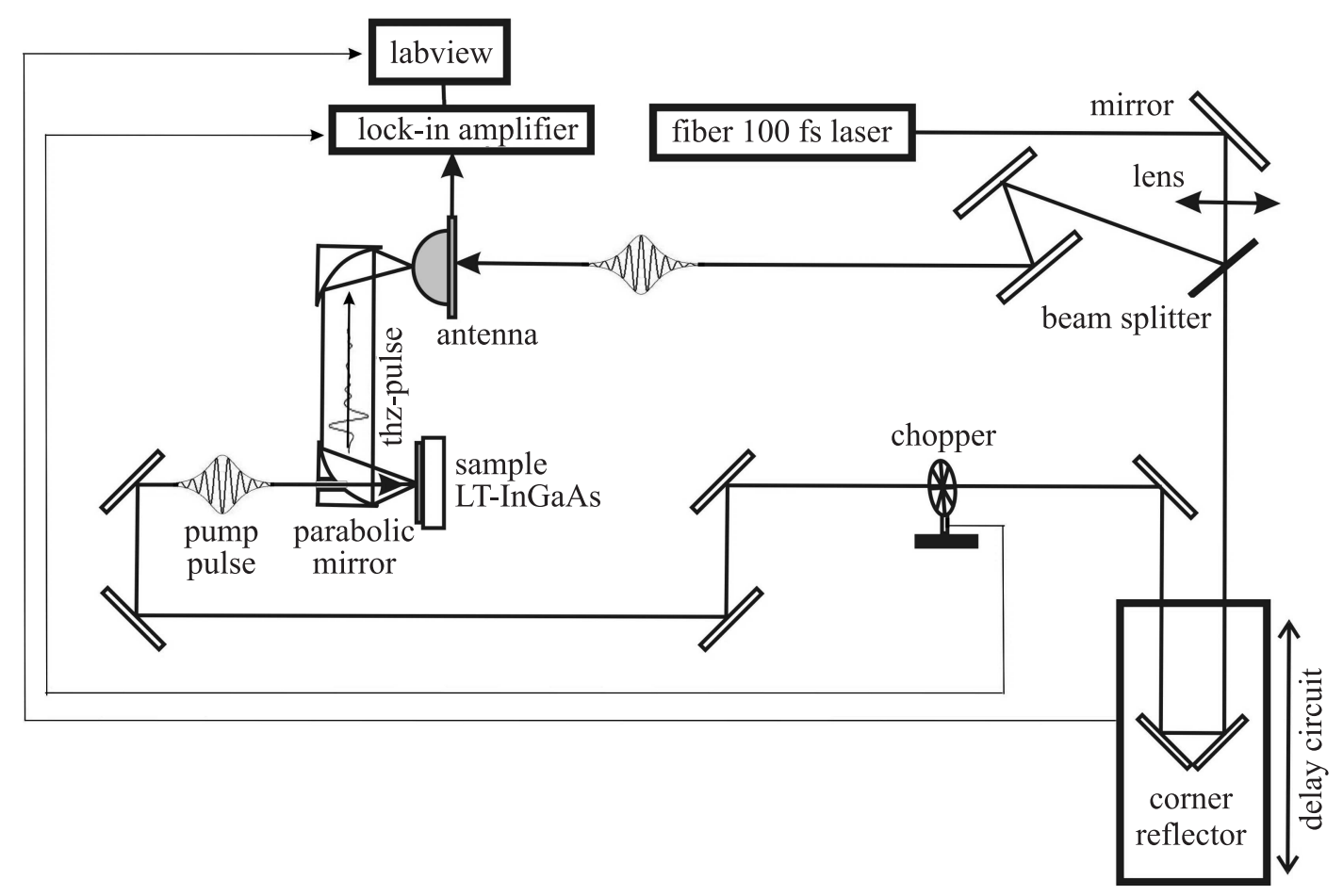

Рис. 2. Схема экспериментальной установки ТСВР.

щей линзы и делителя пучка часть излучения со средней мощностью 20 мВт заводилась через систему зеркал на терагерцевую фотопроводящую антенну-детектор с целью создания свободных носителей в гетероструктуре антенны. Основной пучок мощностью $100 \mathrm{MB}$ направлялся на управляемую линию задержки, затем на механический модулятор пучка, вращающийся с частотой 2.3 кГц, и далее через отверстие в параболическом зеркале попадал на исследуемый образец. Генерируемое в образце терагерцевое излучение собиралось парой параболических зеркал и фокусировалось на кремниевую линзу, интегрированную с терагерцевой антенной. Промодулированный терагерцевым излучением ток свободных носителей антенны регистрировался синхронным детектором. Таким образом измерялась напряженность поля терагерцевых волн, генерируемых во встречном по отношению к накачке направлении „назад“ в различные моменты времени после прихода импульса накачки. Управление всеми узлами установки осуществлялось пакетом программ в системе Labview.

\section{3. Исследование образцов методом АСM}

На рис. 3 представлены АСМ-изображения поверхности исследуемых образцов. Видно, что морфология поверхности образцов зависит от значения $\gamma$, при котором образцы были выращены. При этом зависимость от $\gamma$ для образцов, выращенных на подложках InP (100), более сильная. Для $\gamma \sim 29$ при относительно гладкой поверхности наблюдаются отдельные ямки (образец 983-О). Увеличение $\gamma$ до 90 приводит к образованию более сложного зернистого рельефа поверхности, мелкие зерна (0.2-0.3 мкм) сгруппированы в более крупные агломераты неправильной формы (0.8-1.6 мкм) (образец 985-О).

Поверхность образцов на подложках InP (411)A для $\gamma \sim 29$ мелкозернистая с размером зерен $0.2-0.3$ мкм. Увеличение $\gamma$ до 90 так же, как и для образцов на InP (100), приводит к крупномасштабному рельефу с размером агломератов 0.8-1.6 мкм (образец 985-А). В табл. 1 приведены измеренные значения среднеквадратичной шероховатости поверхности образцов $\left(R_{q}\right)$. Из данных табл. 1 следует, что отжиг образцов на подложках InP (411)A приводит к более сильному увеличению $R_{q}$ по сравнению с образцами на InP (100). Морфология рельефа поверхности после отжига принципиально не изменяется.

Таблица 1. Значение среднеквадратичной шероховатости поверхности образцов LT-InGaAs

\begin{tabular}{|c|c|c|c|c|c|}
\hline \multicolumn{2}{|c|}{ Ориентация подложки } & \multicolumn{2}{|c|}{$(100)$} & \multicolumn{2}{|c|}{$(411) \mathrm{A}$} \\
\hline \multicolumn{2}{|r|}{ Образец } & $983-\mathrm{O}$ & $985-\mathrm{O}$ & 983-A & 985-A \\
\hline \multicolumn{2}{|r|}{$\gamma$} & 29 & 90 & 29 & 90 \\
\hline \multirow[t]{2}{*}{$R_{q}, \mathrm{HM}$} & До отжига & 3.9 & 15.9 & 5.7 & 7.3 \\
\hline & После отжига & 3.7 & 16.3 & 9.0 & 14.3 \\
\hline
\end{tabular}



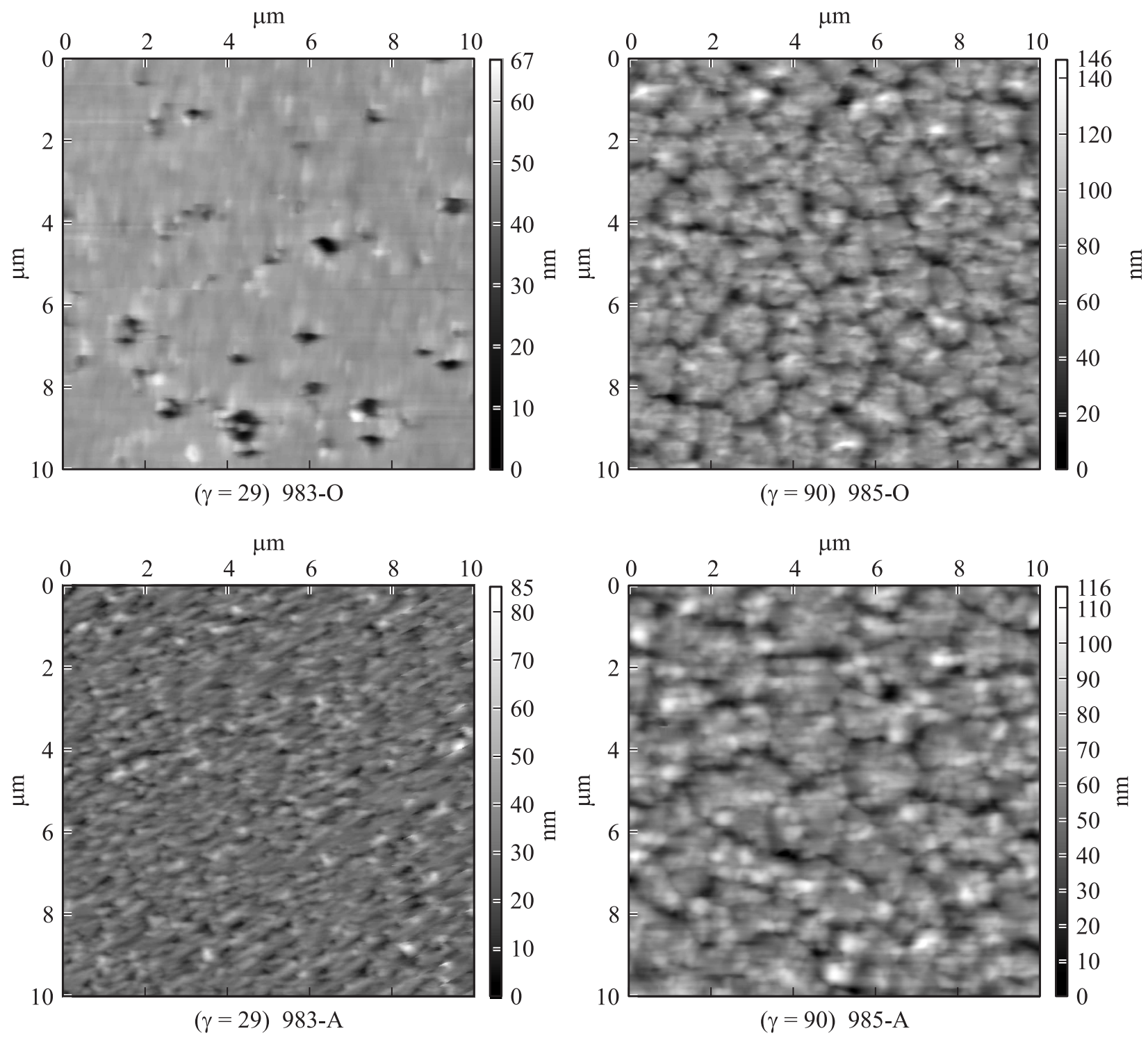

Рис. 3. АСМ-изображения исследуемых образцов после отжига.

Наблюдаемые закономерности изменения морфологии поверхности пленок LT-InGaAs в зависимости от величины потока $\mathrm{As}_{4}$ (более гладкая поверхность соответствует слабому потоку $\mathrm{As}_{4}$, более шероховатая - сильному) находятся в согласии с данными, приведенными в работе [26], касающимися соответствующей температуры роста LT-InGaAs $\left(200^{\circ} \mathrm{C}\right)$.

\section{4. Исследование образцов методом высокоразрешающей рентгеновской дифрактометрии}

В кристаллах со структурой цинковой обманки (к которым относятся InGaAs и InP) дифракционное отражение рентгеновских лучей от плоскостей (411) не происходит, так как нарушается условие одинаковой четности индексов [27]. Поэтому при исследовании об- разцов на подложках InP (411)А наблюдалось отражение от плоскостей (311) с малым углом падения рентгеновского пучка.

На рис. 4 представлены КДО исследуемых образцов до и после отжига. Общим для всех кривых является наличие интенсивного узкого пика, обозначенного 1 , который относится к подложке InP. Отличие КДО образцов, выращенных на (100) и (411)A подложках InP, заключается в следующем: КДО образцов на InP (100) содержат дополнительный пик, обозначенный на рисунках как пик 2, гораздо менее интенсивный и более широкий, чем пик 1. Этот дополнительный пик может располагаться как слева по угловой координате от основного пика (образцы 983-О, 984-О), так и справа (образцы 985О и 986-О). После отжига для образца 983-О пик 2 меняет свое положение относительно пика подложки и смещается в сторону бо́льших углов. Это свидетельствует об уменьшении параметра решетки LT-InGaAs 

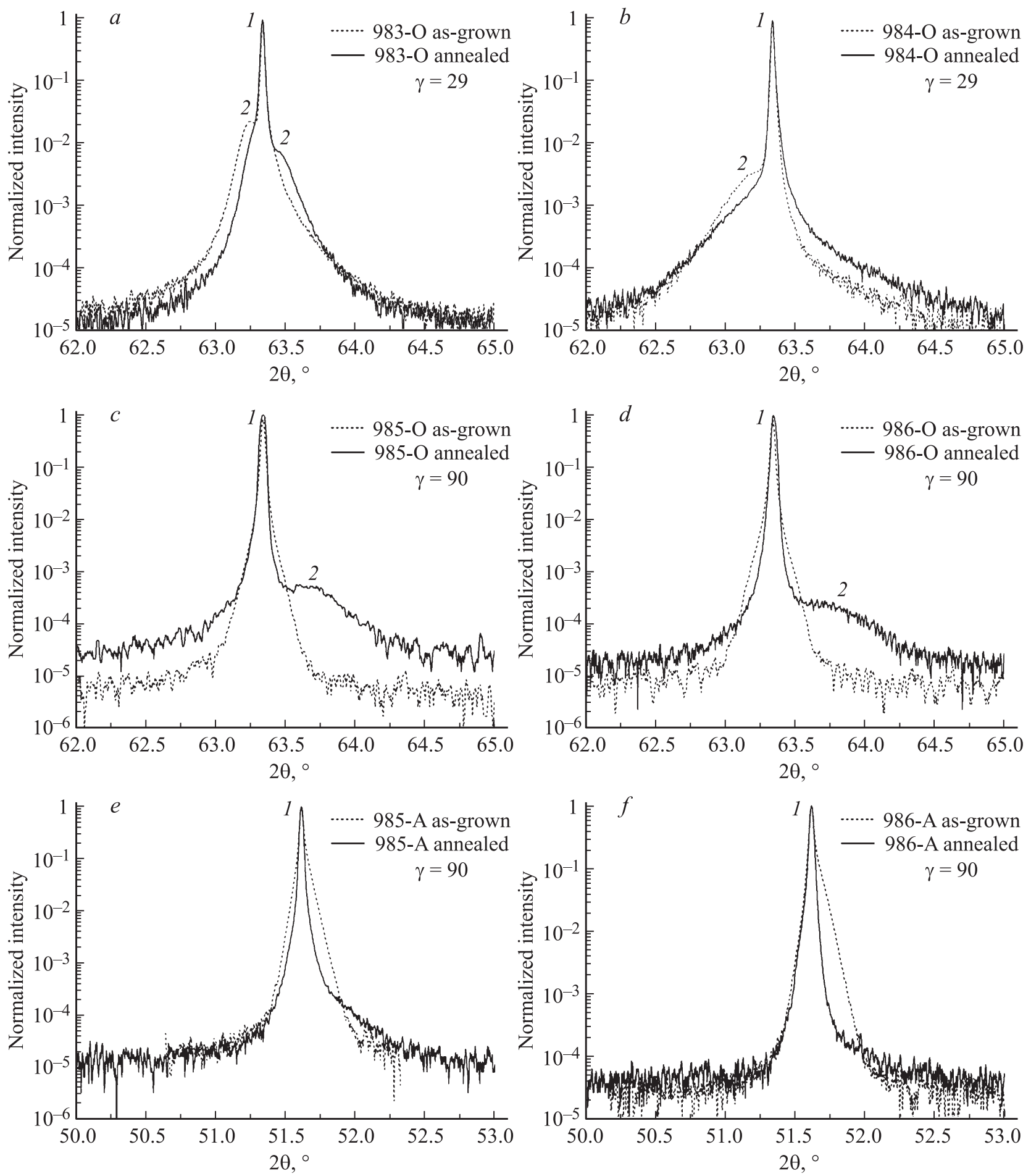

Рис. 4. КДО исследуемых образцов в режиме $\theta / 2 \theta$-сканирования. $a-d-$ образцы на подложках $\operatorname{InP}(100)$, отражение (400); $e, f$ - образцы на подложках InP (411)А, отражение (311).

слоя после отжига. Такое поведение пика 2 характерно только для образцов серий 983 и 984. Отличие этих образцов заключается лишь в том, что слой LT-InGaAs в образце 984 был однородно легирован кремнием с $N_{\mathrm{Si}}=5 \cdot 10^{17} \mathrm{~cm}^{-3}$. Температура $\mathrm{Si}$-ячейки в наших условиях составляла $1040^{\circ} \mathrm{C}$. По нашему мнению, различное поведение пика 2 при отжиге для образцов 983-О и 984-О связано с дополнительным отжигом образца 984-О во время эпитаксиального роста LT-InGaAs за счет радиационного нагрева от источника атомов $\mathrm{Si}$, как в работе [28]. В этой работе сообщается о влиянии нагретых источников легирования ( $\mathrm{Si}$ и $\mathrm{Be})$ на количество избыточного мышьяка в решетке LT-GaAs, что в свою очередь влияет на форму КДО. 

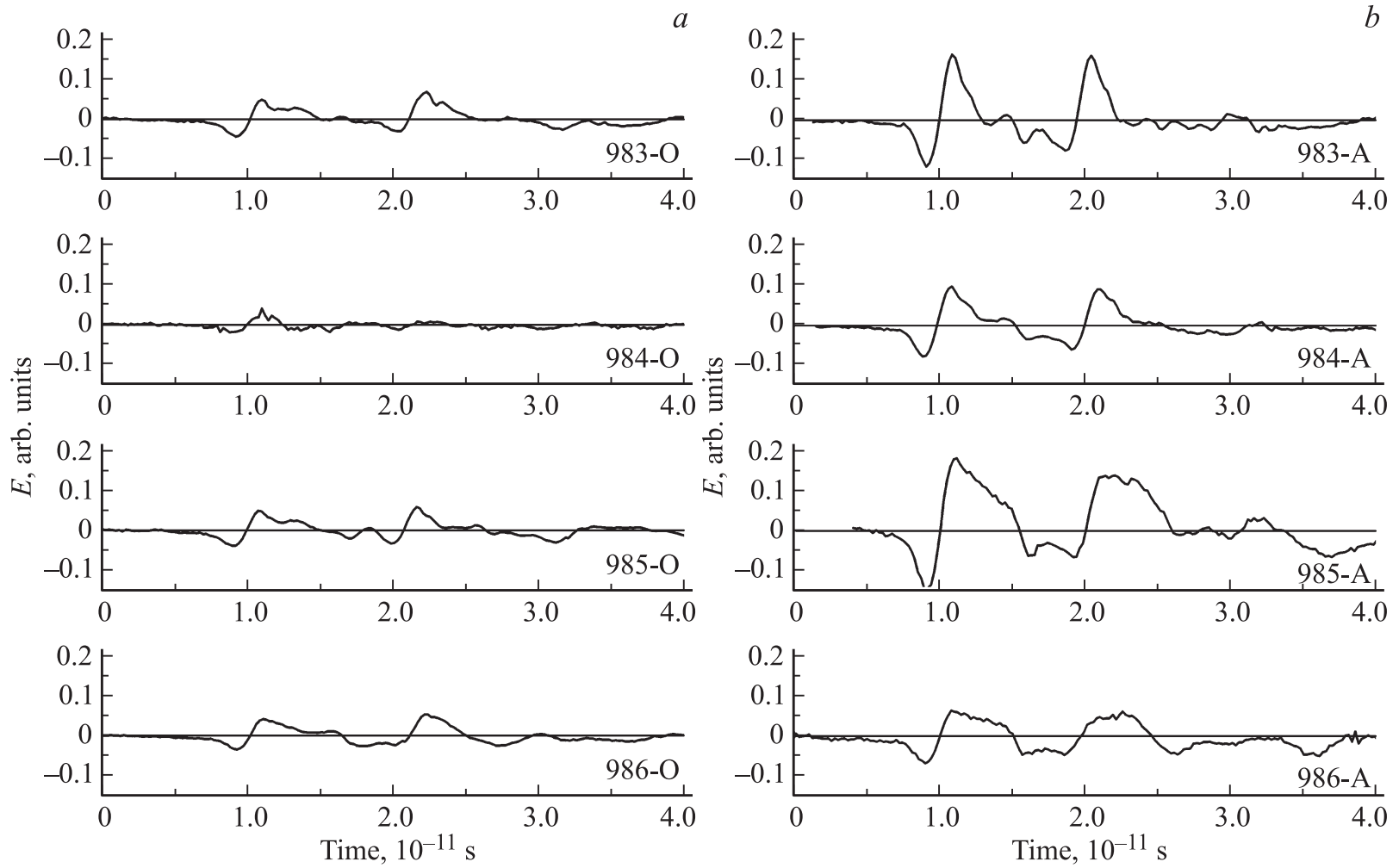

Рис. 5. Зависимости напряженности электромагнитного поля, генерируемого слоями LT-InGaAs, от времени после падения лазерного импульса накачки: $a$ - образцы на подложках InP (100), $b$ - образцы на подложках InP (411)A.

В отличие от образцов на подложках InP (100), КДО образцов на подложках InP (411)A не содержат заметного пика 2; в то же время после отжига пик 1 сужается и справа у него появляется небольшое асимметричное „Плечо“. Это может свидетельствовать о первоначальном совпадении параметров решетки подложки InP и LT-InGaAs пленки, из-за чего пик 2 оказывается замаскирован пиком 1, и об увеличении параметра решетки LT-InGaAs после отжига.

Значения параметра решетки LT-InGaAs слоя, рассчитанные по угловому положению пика 2, приведены в табл. 2.

\section{5. Исследование образцов методом терагерцевой спектроскопии временно́го разрешения}

На рис. 5, $a, b$ приведены измеренные временны́е зависимости напряженности электромагнитного поля, гене- рируемого во всех исследованных образцах LT-InGaAs. После межзонного поглощения импульсов излучения накачки фотовозбужденные электроны и дырки под действием электрического поля формировали быстро меняющийся электрический ток. Всплески тока приводили к генерации импульсов электромагнитного излучения. Так как на исследуемых образцах не были сформированы омические контакты и к ним не прикладывалось внешнее напряжение, движение фотовозбужденных носителей заряда происходило под действием встроенного электрического поля (поверхностный потенциал) либо за счет различной диффузионной длины электронов и дырок (эффект Дембера). Волновые формы детектируемых сигналов во всех случаях состоят из двух импульсов приблизительно одинаковой формы и амплитуды, отстоящих друг от друга во времени. Второй импульс, наблюдаемый через примерно 10 пс после первого, не связан с отражением терагерцевой волны от подложки InP, так как коэффициент поглощения фосфида индия в этом частотном диапазоне довольно значителен и достигает

Таблица 2. Значение параметров решетки LT-InGaAs слоев

\begin{tabular}{c|l|c|c|c|c|c|c}
\hline \multicolumn{2}{c|}{ Образец } & $983-\mathrm{O}$ & $984-\mathrm{O}$ & $985-\mathrm{O}$ & $985-\mathrm{A}$ & $986-\mathrm{O}$ & $986-\mathrm{A}$ \\
\hline$a$, & Неотожженный & $5.877 \pm 0.001$ & $5.887 \pm 0.005$ & $-^{*}$ & - & - & - \\
$\AA$ & Отожженный & $5.856 \pm 0.002$ & - & $5.835 \pm 0.007$ & - & $5.832 \pm 0.007$ & -
\end{tabular}

Примечание. * „-““ означает отсутствие пика на КДО. 
Таблица 3. Максимальные значения напряженности генерируемого поля (усл. ед.)

\begin{tabular}{c|c|c|c|c|c}
\hline \multirow{2}{*}{$\begin{array}{c}\text { Ориентация } \\
\text { подложки }\end{array}$} & \multicolumn{5}{|c}{ Образец } \\
\cline { 2 - 6 } & 983 & 984 & 985 & 986 & $\operatorname{InP}$ \\
\hline$(100)$ & 0.07 & 0.05 & 0.06 & 0.06 & 0.01 \\
$(411) \mathrm{A}$ & 0.17 & 0.10 & 0.19 & 0.07 & 0.02
\end{tabular}

порядка $100 \mathrm{~cm}^{-1}$ [29], а наблюдаемый второй сигнал не уступает основному по амплитуде. Измерения ТСВР на пустых подложках InP (100) и (411)A без LT-InGaAs показали, что в подложках генерация отсутствует либо на 1-2 порядка слабее, чем в гетероструктурах с LT-InGaAs. Таким образом, наблюдаемые сигналы терагерцевого излучения генерируются в слоях LT-InGaAs микронной толщины. Согласно оценкам, более поздний импульс связан с переотражением лазерной накачки от задней стороны подложки InP толщиной 400 мкм c последующей генерацией терагерцевого излучения в микронном слое LT-InGaAs в геометрии „вперед“. C учетом небольшого поглощения лазерной накачки в материале подложки и потерь при отражении накачки от матовой задней поверхности образцов можно заключить, что эффективность генерации в направлении накачки должна быть несколько больше, чем во встречном направлении.

Из рис. 5 видно, что во всех образцах, выращенных на подложках InP ориентации (411)A, амплитуда генерируемых волн приблизительно в 2 раза выше, чем в образцах на InP (100). Для сравнения в табл. 3 приведены максимальные значения напряженности электрического поля, зарегистрированного от образцов различного типа (в одних и тех же относительных единицах).

С целью определения спектрального состава генерируемых импульсов производилась процедура фурьепреобразования временнь́х форм. Полученные таким образом нормированные частотные распределения спектральных амплитуд сигналов от образцов 985 и 986 в пределах хорошей точности не зависели от ориентаций подложки (411)А или (100). Однако было обнаружено, что спектральные формы излучения от образцов серий 983 и 984 существенным образом зависят от типа подложки. Как видно из сравнения рис. 5, $a$ и $b$, образцы, выращенные на подложках InP (411)A, генерируют более интенсивное высокочастотное излучение, нежели образцы на InP (100). Можно сделать вывод, что в эпитаксиальных пленках LT-InGaAs, выращенных на подложках InP (411)A, увеличена концентрация ловушек $\mathrm{As}_{\mathrm{Ga}}^{+}$либо образуются ловушки, связанные с другими точечными дефектами, которые захватывают электроны более эффективно.

Использование более высокого давления $\mathrm{As}_{4}$ при выращивании пленок LT-InGaAs ( $\gamma \sim 90$ вместо 29) привело к изменению формы временно́й зависимости импульса, что сказалось на спектральном составе излучения. На рис. 6 приведены спектральные зависимости интенсивности излучения, генерируемого в образцах 983-A и 985-A на подложках InP (411)A. При расчетах учитывалась амплитудно-частотная характеристика детектирующей антенны. Зарегистрированные спектры генерации излучения образцов лежат в диапазоне 50-600 ГГц. На частотах ниже 50 ГГц чувствительность фотопроводящей антенны падает более чем на порядок, поэтому точный вывод о спектральном отклике образцов в этом диапазоне сделать нельзя. При этом в образцах, выращенных при высоком давлении $\mathrm{As}_{4}$, максимум спектра излучения слегка сдвинут в более низкочастотную область и по амплитуде в 2 раза превосходит максимум спектра генерации в образцах, выращенных при низком давлении $\mathrm{As}_{4}$. Это свидетельствует о более эффективной генерации на частотах, меньших 200 ГГц, в образцах с бо́льшим числом электронных ловушек на дефектах.

Легирование слоев LT-InGaAs атомами Si привело к снижению амплитуды напряженности терагерцевого излучения приблизительно в 2 раза (интенсивности приблизительно в 4 раза) во всех случаях: для обоих типов подложек и для двух использованных давлений $\mathrm{As}_{4}$. При этом форма временно́й зависимости импульсов излучения и спектральный состав излучения не зависели от наличия или отсутствия примесей $\mathrm{Si}$ в слоях LT-InGaAs. Возможное объяснение заключается в том, что, как упоминалось во Введении, антиструктурные дефекты $\mathrm{As}_{\mathrm{Ga}}$ функционируют как ловушки электронов только в заряженном, безэлектронном состоянии $\mathrm{As}_{\mathrm{Ga}}^{+}$. А когда в вещество вводится донорная примесь $\mathrm{Si}$, электроны с уровней $\mathrm{Si}$ переходят на уровни $\mathrm{As}_{\mathrm{Ga}}$ и заполняют их. Следовательно, концентрация активных ловушек $\mathrm{As}_{\mathrm{Ga}}^{+}$уменьшается, ток фотовозбужденных носителей заряда изменяется во времени слабее и интенсивность терагерцевого излучения падает.

Таким образом, представленные данные показывают, что для источников терагерцевого излучения использование подложек InP с ориентацией $(n 11) \mathrm{A}$ может оказаться более предпочтительным. Использование других

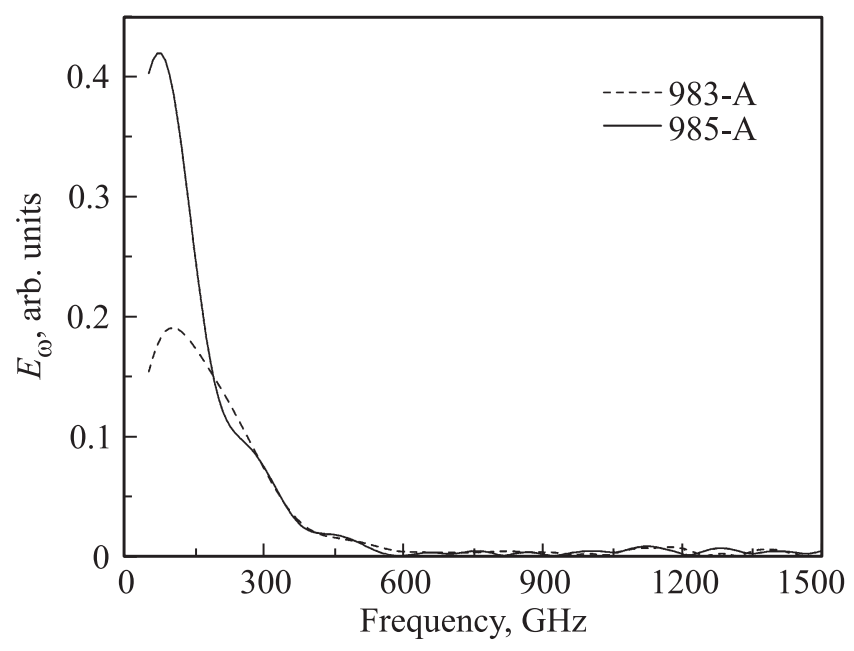

Рис. 6. Спектр импульсов, генерируемых в образцах 983-А и 985-А на подложках InP (411)A. 
манипуляций с LT-InGaAs слоями, упомянутых выше, может повысить качественные и количественные характеристики устройств, выполненных на базе LT-InGaAs структур с ориентациями (n11)A по сравнению с ориентацией (100).

\section{6. Заключение}

Пленки LT- $\operatorname{In}_{0.53} \mathrm{Ga}_{0.47} \mathrm{As}$, выращенные при низком давлении $\mathrm{As}_{4}(\gamma=29)$, обладают умеренно шероховатой поверхностью $\left(R_{q}=4-9\right.$ нм $)$, а при увеличении давления $\mathrm{As}_{4}(\gamma=90)$ шероховатость поверхности пленок значительно возрастает $\left(R_{q}=14-16 \mathrm{HM}\right)$. При этом использование подложек InP с ориентацией (411)А несколько увеличивает шероховатость поверхности образцов, выращенных при одинаковом значении $\gamma$. Выявлено, что на структурное совершенство пленок LT-InGaAs гораздо большее влияние оказывает давление $\mathrm{As}_{4}$, чем ориентация подложки.

При облучении исследуемых образцов фемтосекундными импульсами инфракрасного волоконного $\mathrm{Er}^{3+}$-лазера генерируется излучение в полосе частот до 300 ГГц с максимумом при $~ 70-100$ ГГц.

Обнаружено, что генерация терагерцевого излучения пленками LT-InGaAs на подложках InP с кристаллографической ориентацией поверхности (411)А в 3-5 раз эффективнее, чем такими же пленками на подложках InP с ориентацией (100).

Использование более высокого давления $\mathrm{As}_{4}$ при выращивании пленок LT-InGaAs ( $\gamma \sim 90$ вместо 29) приводит к изменению временной формы терагерцевого импульса, что сказывается на спектре терагерцевого излучения: его максимум смещается в сторону меньших частот. Интегральная интенсивность терагерцевого излучения при этом увеличивается.

Легирование пленок LT-InGaAs атомами Si приводит к снижению амплитуды терагерцевого излучения приблизительно в 2 раза (интенсивности $\sim$ в 4 раза), временна́я форма и спектральный состав импульсов излучения не изменяются.

Авторы выражают благодарность канд. физ.-мат. наук Д.В. Лопаеву за помощь в организации экспериментов.

Работа выполнена при поддержке РФФИ (гранты № 16-02-00258, 16-29-03294, 16-32-00693, 16-07-00187 A), а также при поддержке стипендии президента Российской Федерации (СП-686.2016.3).

\section{Список литературы}

[1] E.A.P. Prieto, S.A.B. Vizcara, A.S. Somintac, A.A. Salvador, E.S. Estacio, C.T. Que, K. Yamamoto, M. Tani. J. Opt. Soc. Amer. B, 31 (2), 291 (2014).

[2] A. Krotkus. J. Phys. D: Appl. Phys., 43, 273001 (2010).

[3] A. Krotkus, K. Bertulis, L. Dapkus, U. Olin, S. Marcinkevičius. Appl. Phys. Lett., 75, 3336 (1999).
[4] Patent US 8835853. Photoconductive element / Toshihiko Ouchi, Kousuke Kajiki; Canon Kabushiki Kaisha, Tokyo.Publication date 16.09.2014.

[5] J.-L. Coutaz, J.-F. Roux, A. Gaarder, S. Marcinkevicius, J. Jasinski, K. Korona, M. Kaminska, K. Bertulis, A. Krotkus. XI International Semiconducting and Insulating Material Conference (Canberra, Australia, 3-7 July 2000) p. 89.

[6] P. Specht, S. Jeong, H. Sohn, M. Luysberg, A. Prasad, J. Gebauer, R. Krause-Rehberg, E.R. Weber. Mater. Sci. Forum, 258-263, 251 (1997).

[7] J. Maguire, R. Murray, R.C. Newman, R.B. Beall, J.J. Harris. Appl. Phys. Lett., 50 (9), 516 (1987).

[8] E.F. Schubert, J.E. Cunningham, W.T. Tsang. Sol. St. Commun., 63 (7), 591 (1987).

[9] Y. Okano, H. Seto, H. Katahama, S. Nishine, I. Fujimoto, T. Suzuki. Jpn. J. Appl. Phys., 28 (2), L151 (1989).

[10] F. Piazza, L. Pavesi, M. Henini, D. Johnston. Semicond. Sci. Technol., 7, 1504 (1992).

[11] L. Pavesi, F. Piazza, M. Henini, I. Harrison. Semicond. Sci. Technol., 8, 167 (1993).

[12] M. Henini, N. Galbiati, E. Grilli, M. Guzzi, L. Pavesi. J. Cryst. Growth, 175-176, 1108 (1997).

[13] Г.Б. Галиев, В.Э. Каминский, В.Г. Мокеров, Л.Э. Велиховский. ФТП, 35 (4), 427 (2001).

[14] G.B. Galiev, V. Kaminskii, D. Milovzorov, L. Velihovskii, V.G. Mokerov. Semicond. Sci. Technol., 17 (2), 120 (2002).

[15] Г.Б. Галиев, Е.А. Климов, М.М. Грехов, С.С. Пушкарев, Д.В. Лаврухин, П.П. Мальцев. ФТП, 50 (2), 195 (2016).

[16] Д.В. Лаврухин, А.Э. Ячменев, А.С. Бугаев, Г.Б. Галиев, Е.А. Климов, Р.А. Хабибуллин, Д.С. Пономарев, П.П. Мальцев. ФТП, 49 (7), 932 (2015).

[17] S. Adashi. Properties of Semiconductor Alloys: Group-IV, III-V and II-VI Semiconductors (John Wiley \& Sons, Ltd., 2009).

[18] J. Mangeney, F. Meng, D. Gacemi, E. Peytavit, J.F. Lampin, T. Akalin. Appl. Phys. Lett., 97, 161109 (2010).

[19] J. Mangeney, N. Chimot, L. Meignien, N. Zerounian, P. Crozat, K. Blary, J.F. Lampin, P. Mounaix. Opt. Express, 15 (14), 8943 (2007).

[20] B. Sartorius, H. Roehle, H. Kunzell, J. Böttcher, M. Schlak, D. Stanze, H. Venghaus, M. Schell. Opt. Express, 16 (13), 9565 (2008).

[21] A. Takazato, M. Kamakura, T. Matsui, J. Kitagawa, Y. Kadoya. Appl. Phys. Lett., 91, 011102 (2007).

[22] C.D. Wood, O. Hatem, J.E. Cunningham, E.H. Linfield, A.G. Davies, P.J. Cannard, M.J. Robertson, D.G. Moodie. Appl. Phys. Lett., 96, 194104 (2010).

[23] F. Ospald, D. Maryenko, K. von Klitzing, D.C. Driscoll, M.P. Hanson, H. Lu, A.C. Gossard, J.H. Smet. Appl. Phys. Lett., 92, 131117 (2008).

[24] M. Sukhotin, E.R. Brown, D. Driscoll, M. Hanson, A.C. Gossard. Appl. Phys. Lett., 83 (19), 3921 (2003).

[25] D.C. Driscoll, M. Hanson, C. Kadow, A.C. Gossard. Appl. Phys. Lett., 78 (12), 1703 (2001).

[26] М.Д. Вилисова, И.В. Ивонин, Л.Г. Лаврентьева, С.В. Субач, М.П. Якубеня, В.В. Преображенский, М.А. Путято, Б.Р. Семягин, Н.А. Берт, Ю.Г. Мусихин, В.В. Чалдышев. ФТП, 33 (8), 900 (1999).

[27] Б.К. Вайнштейн. Современная кристаллография (М., Наука, 1979) т. 1.

[28] M. Missous. Microelectronic J., 27, 393 (1996). 
[29] C. Zhang, B. Jin, J. Chen, P. Wu, M. Tonouchi. J. Opt. Soc. Am. B, 26 (9), A1 (2009).

Редактор А.Н. Смирнов

\section{Terahertz radiation from}

low-temperature-grown epitaxial

films InGaAs on (100) and (411)A
oriented InP substrates

G.B. Galiev' ${ }^{1}$, M.M. Grekhov ${ }^{3}$, G.Kh. Kitaeva ${ }^{2}$,

E.A. Klimov' ${ }^{1}$, A.N. Klochkov' ${ }^{1}$, O.S. Kolentsova ${ }^{3}$,

V.V. Kornienko ${ }^{2}$, K.A. Kuznetsov' ${ }^{2}$,

P.P. Maltsev ${ }^{1}$, S.S. Pushkarev ${ }^{1}$

${ }^{1}$ Institute of Ultra High Semiconductor Electronics,

Russian Academy of Sciences,

117105 Moscow, Russia

${ }^{2}$ M.V. Lomonosov Moscow State University,

Faculty of Physics,

119991 Moscow, Russia

${ }^{3}$ National Research Nuclear University „MEPhl“,

115409 Moscow, Russia

Abstract $\operatorname{In}_{0.53} \mathrm{Ga}_{0.47}$ As films were grown by molecular-beam epitaxy on (100) and (411)A oriented InP substrates at low temperature $200^{\circ} \mathrm{C}$ and variable arsenic pressure. Surface morphology and crystal structure quality were investigated by atomic-force microscopy and high-resolution $X$-ray diffraction, respectively. Terahertz radiation generated by films under femtosecond fiber $\mathrm{Er}^{3+}$-laser pumping was investigated by terahertz time-domain spectroscopy. Terahertz radiation from LT- $\operatorname{In}_{0.53} \mathrm{Ga}_{0.47} \mathrm{As}$ films grown on (411)A InP substrates is revealed to be $3-5$ times intensive than radiation from films grown on (100) InP substrates. Consequently, growing LT-InGaAs films on $(n 11)$ A oriented InP substrates $(n=1,2,3, \ldots)$ is perspective for terahertz radiation sources engineering. 